\title{
Entre o imperialismo e a imaginação, a construção da Geografia Tropical em Pierre Gourou
}

\section{Between imperialism and imagination, the construction of Tropical Geography in the view of Pierre Gourou}

\author{
Antonio Carlos Vitte \\ Universidade Estadual de Campinas
}

Resumo: As reflexões de Pierre Gourou sobre o mundo tropical, particularmente o sudoeste asiático, representa um importante marco nas relações entre a geografia e o imperialismo. A partir de influências da medicina e de uma concepção de que os trópicos representavam a antítese do mundo europeu temperado, o discurso geográfico de Gourou formaliza uma visão míope sobre o mundo tropical e seus habitantes.

Palavras-chave: História da geografia. Geografia francesa. Mundo tropical. Pierre Gourou. Segregação.

\begin{abstract}
The reflections of Pierre Gourou on the tropical world, particularly on Southeast Asia, represent an important milestone in the relations between Geography and imperialism. From influences of Medicine and a notion that the tropics represented an antithesis of the temperate European world, Gourou's geographical speech formalizes a short-sighted view of the tropical world and its inhabitants.
\end{abstract}

Keywords: History of Geography. French Geography. Tropical world. Pierre Gourou. Segregation. 


\section{INTRODUÇÃO}

A transformação do Globo em Terra é historicamente construída a partir de uma variedade de caminhos, que muitas vezes se intercruzam, mas cada um deles marcado por experiências, vivências, estudos científicos e acima de tudo por imaginações e imaginários que fundamentam a representação da natureza e dos lugares. A construção geográfica dos lugares envolve uma teia de relações da qual participam a história, a geografia cultural, a literatura, a história da ciência e a própria história imperial, o que levou Said (2005) a falar em "guerras das geografias".

Neste trabalho,nos propomos a compreender a genealogia da chamada geografia tropical, focando o trabalho do geógrafo francês Pierre Gourou (1900-1999), que com sua concepção de geografia tropical, contribuiu na manutenção do imperialismo francês no sudoeste da Ásia, interferindo na produção acadêmica e curricular dos cursos de geografia do restante do mundo.

Sob o ponto de vista metodológico, fazemos uso das noções de ideologia geográfica (MORAES, 1988) e de orientalismo de Edward Said (SAID, 1979), para demonstrar que a imagem de trópico sempre foi veiculada por meio de linguagens e imagens sempre negativas, nas quais os trópicos foram vistos como espaços da degeneração, do atraso e da indolência. Com isto, produziu-se uma clara distinção entre o mundo europeu e o tropical, da mesma forma como foi produzida uma distinção entre o ocidente e o oriente (SAID, 1979, 1994).

\section{A CONSTRUÇÃO SIMBÓLICA DO SISTEMA TERRA-MUNDO}

Denis Cosgrove alerta-nos para o fato de que não devemos menosprezar o processo de constituição do capitalismo e a conquista do globo, mas por outro lado, não podemos nos esquecer de que o ser humano também vive de subjetividades e de imaginação (COSGROVE, 2001). Assim, por exemplo, para os alemães Alexander von Humboldt, Wolfgang von Goethe e Carl Ritter, a Terra era possuidora de uma força vital e predominava uma harmonia entre os seus elementos (COSGROVE, 2001, p. 3). O renascimento e a revolução cartesiana provocaram uma mudança no sentido e no significado da luz e da visão, de tal forma que a Terra passou a ser representada cada vez de forma mais complexa pela humanidade com o auxílio da geometria, da literatura e das demais artes (COSGROVE, 2001, p. 5). Assim, os corpos passaram a ser representados como esféricos e suas relações foram construídas com o auxílio da imaginação. A mesma imaginação que construiu a noção de rotação da Terra, das épocas e estações do ano, assim como uma cosmologia e uma geografia que explicassem as diferentes formas de vida na superfície da Terra.

Então, o globo e a natureza são o produto de uma construção cultural e histórica, sempre com variados níveis de complexidade, dependendo da dimensão escalar que tomemos para análise. Para Cosgrove (2001, p.6), a revolução copernicana é quem trouxe para o centro do debate o pensamento e as imagens cosmográficas do globo e da natureza. Neste processo, cada vez mais a cosmografia, geografia e cartografia são indissociáveis e intimamente conectadas através das práticas históricas e que levaram a construção dos conceitos de região e lugar. Cosgrove (2001, p.6-7) chega a falar em "globalismo", 
expressão que para ele representaria esta complexa relação $m$ qual atua atua também a imaginação e permite-nos construir uma imagem estóica do mundo, da natureza e de nossa existência. Para o autor, este processo seria produto de uma auto-reflexão da sociedade, que a cada momento foi incorporando novos espaços até então desconhecidos; esta situação colocou para a sociedade européia um problema, o qual seja, como construir a consciência individual e coletiva deste novo mundo que estava sendo construído? Daí, a concepção de que a natureza seria uma universalidade empírica e a Terra seria nosso campo de ação e ao mesmo tempo a materialização social e cultural desta universalidade (COSGROVE, 2001, p.6-7).

Para o filósofo português Leonel Ribeiro dos Santos, este estoicismo foi implantado por Immanuel Kant, particularmente em sua Crítica do Juízo (SANTOS, 2009, p.118161) e que passou a representar o modelo de natureza, sistematizado pela razão humana, que valorizou o equilíbrio e a harmonia entre seus elementos. Kant, ao transformar a noção de espaço [Raum] da astronomia e da geometria, motivado pelas críticas de Herder e pela noção de Buildengstrib de Blumenbach, que são como uma revolução na biologia, permitindo o desenvolvimento de organismo e de epigênese das espécies; Kant viu na Geografia Física a possibilidade epistemológica de entender a natureza não mais como globo, mas sim como Terra e o desenvolvimento da humanidade como uma interação, um metabolismo entre o sistema-terra e o sistema-mundo, fato que influenciou uma geração de naturalistas como Alexander von Humboldt, historiadores e linguistas, como Wilhelm von Humboldt e geógrafos, como Carl Ritter, e seus discípulos Fröbel e Wappäus (TATHAM, 1960); além do próprio Ratzel, que com sua obra Über Naturschilderung (RATZEL, 1906) procurou retomar a estética e a pintura de paisagem desenvolvidas por Humbodt, a partir das influências kantianas, para assim reposicionar epistemológica e metodologicamente a Ciência Geográfica, durante a passagem dos séculos XIX ao XX, perante as Ciências Sociais (CARVALHO, 1999). O fato é que resgatando Said (2005) vivíamos uma crise imperial dada pelas próprias circunstâncias materiais e espirituais como o imperialismo global e o seu sentido de humanidade e de natureza iria sendo construído. Daí a participação da geografia e das demais ciências na contrução de um discurso, uma prática e uma visão simbólica que justificasse a integração dos novos espaços aos centros imperiais do século XIX. Um controle imperial que se impõem sobre o Globo, transformando-o em Terra, onde a natureza, enquanto universal, encontra seu limite na dimensão cultural do humano. Para Cosgrove (2001, p.19) esta situação passou a ser lentamente construída desde o Império de Alexandre Magno, mas foi com a união de Roma com o Cristianismo que foram, de fato, marcadas as fronteiras do domínio imperial. Com a frase urbs et orbis terrarum (COSGROVE, 2001, p.18) Roma permite a expansão do imaginário imperial para além das colunas de Hercules e ao mesmo tempo impõem uma separação entre a cidade e a natureza, entre o céu e a Terra, fato que ao longo dos tempos viabilizou a instrumentalização cartográfica e as navegações de Bougainville e do capitão Cook no pacífico.

O mundo tropical passa a ser incorporado na lógica imperial capitalista logo após o domínio napoleônico na Europa, em que se destacou a Bélgica, primeiro império a ocupar as regiões Tropicais da África. Neste momento, a monarquia belga descobre uma série de estruturas iconográficas do mundo tropical africano que passam a ser 
incorporadas através de museus, livros e palestras, que demonstram que os povos da África possuíam características culturais e sociais de se relacionarem entre-si e com a natureza, totalmente diferente da européia. Com isto, o imperialismo assume como tarefa primordial a necessidade de confrontar e explicar as diferenças geográficas da natureza e da cultura, surgindo disto o conceito de oikoumene, o limite da cultura. A cidade européia é vista como ponto máximo da evolução hierárquica na Terra e seria a única capaz de se conectar com o espaço celeste e com o tempo celestial (COSGROVE, 2001, p.20).

Portanto, o imperialismo começa a criar uma hierarquia espaço-temporal entre as diversidades de natureza e de cultura, cabendo à cartografia delimitar as diversidades da natureza na Terra, enquanto que a geografia procurava explicar a gênese dos diferentes fenômenos naturais e culturais.

É assim que a imagem de mundo tropical foi produzida por europeus, onde os lugares tropicais foram construídos por meio da experiência e dos trabalhos de campo, que, no processo de conhecimento dos lugares e suas diferenciações, construiu-se a generalização da noção de tropicalidade.

Alexander von Humboldt, influenciado pela Geografia e pela filosofia kantiana (VITTE e SILVEIRA, 2010), considerava que a Geografia tratava tanto da história natural, quanto das formas e processos atuais. Assim, influenciado pelo geólogo Werner, Humboldt considerava inicialmente a Geografia como sendo uma "Geonosia", ou seja, uma Weltbeschereibung, cuja função era discutir a distribuição espacial dos fenômenos na superfície da Terra.

O conceito de Trópico e sua delimitação geográfica ocorreu somente a partir da comparação com as regiões temperadas, onde predominava a cultura, a civilização e o ritmo ameno e harmonioso da natureza. Ao contrário, no mundo tropical, que encantou pelo sublime da natureza, passou a predominar a noção da degeneração natural e moral dos homens, um espaço da negatividade.

Os conceitos de trópico e detropicalidade, conhecidos ainda hoje, foram produzidos durante os séculos XVIII e XIX a partir de um intercruzamento entre a razão romântica, representada pela ciência humboldtiana, as práticas imperialistas e os avanços da ciência provocados pela incorporação do positivismo em meados do século XIX. O resultado desse complexo intercruzamento foi a produção discursiva, imagética e, portanto, simbólica sobre as belezas do mundo natural tropical, vis-avis a "fraqueza" e a "indolência" de seus habitantes, discurso ideológico que deve ser entendido no contex to do imperialismo, quando a produção do conhecimento geográfico esteve fortemente vinculada às ações do Estado- Nação, criando assim as chamadas escolas nacionais de geografia (CLAVAL, 2003).

\section{A PRODUÇÃO DA IMAGEM DOS TRÓPICOS}

O mundo tropical é demarcado por dois paralelos de latitude ao redor da Terra, uma $23^{\circ} 27^{\prime}$ ao norte do Equador e outro $23^{\circ} 27^{\prime}$ ao sul da linha do Equador. Essa marca coincide com os círculos do trópico de Câncer e Capricórnio, conhecidos desde os tempos da Grécia Clássica. Esses círculos delimitavam a "zona tórrida", onde haveria uma série de coincidências astronômicas, astrológicas, cosmográficas e míticas, caracterizada segundo os gregos, pelo limite natural e moral (COSGROVE, 2001, p.29-53).

Outra interpretação possível, a partir de uma herança humboldtiana, é aquela na qual os trópicos permitem uma experiência completamente diversa para um europeu, com novas espécies de animais, relevo, 
solos, evento meteorológico e climático, marcando uma zona geográfica particular.

Os trópicos foram incluídos no moderno pensamento ocidental a partir dos trabalhos de Alexander von Humboldt (1769-1859), resultantes de suas viagens à América Equinocial (HUMBOLDT, 1995). Humboldt foi influenciado pelo sublime kantiano, pela noção de experiência estética de Schiller e pelo conceito de morfologia de Goethe e produziu as mais belas descrições e registros pictóricos sobre as florestas tropicais, as montanhas tropicais, os desertos, os rios e as ilhas tropicais. Longe das divagações que reinaram nos séculos XV e XVI, os séculos XVIII e XIX caracterizaram-se pelas viagens, suas descrições in situ das paisagens e de seus conteúdos, feitas com a utilização de instrumentos para medir e registrar os fatos cotidianos da natureza do mundo tropical, bem como pelas pinturas de paisagens (STAFFORD, 1982).

Assim, a imagem de trópico durante o século XVIII esteve muito ligada à figura de Alexander von Humboldt, que exerceu forte influência em várias gerações de naturalistas e artistas europeus. A ciência humboldtiana contribuiu para a consolidação da estética da paisagem tropical, na qual a vegetação luxuriante dos trópicos foi concebida como o máximo do sublime e da arte natural, sendo o mundo tropical visto como um local privilegiado que permitia observar a natureza em toda a sua grandiosidade (NICHOLSDON, 1959).

Essa concepção estética da paisagem natural marcou profundamente as futuras gerações. Tanto assim, que quando Charles Darwin esteve no Rio de Janeiro em abril de 1832, comentou como "a tropical Forest in all its sublime grandeur", cuja cena demandava um verdadeiro trabalho filosófico para o entendimento da natureza. "I formerly admired Humboldt, I now almost adore him; He alone gives any notion of the feelings which are raised in the mind of first entering the Tropics" (DARWIN, 1832 apud CANNON, 1978, p.87, MARTINS, 2000).

A visão do mundo natural de Humboldt foi essencialmente fisiográfica, pois ela tinha como preocupação a distribuição espacial dos fenômenos naturais sobre a superfície da Terra e sua representação visual, na forma de mapas e de iso-mapas (DETTELBACH, 1999).

Humboldt desenvolveu a concepção de mundo tropical com base no uso de instrumentos técnicos e representações refinadas da fisionomia da paisagem, combinando a representação gráfica com descrições textuais e com um estilo narrativo que clamava pelo princípio da experiência estética de Schiller, desenvolvendo, assim o princípio da espacialidade.

O produto desta "descoberta" dos trópicos foi a geração de uma epistemologia das ciências naturais contemporâneas, a partir do reconhecimento das diferentes espécies naturais que foram importantes para a produção da imagem visual do mundo tropical e que é a matriz das disciplinas da geografia física. Essa importância se solidificou a partir do momento em que a geografia foi incorporada ao sistema educacional e foi iniciada a produção de mapas e globos que foram utilizados em sala de aula por inúmeros professores. John Ruskin (1904) propôs, por exemplo, o uso do globo terrestre nas escolas inglesas; globo esse dividido em círculos latitudinais, tendo cada círculo um nome, o círculo árabe, o veneziano e o cristão. A zona tropical recebeu os nomes de santos e apóstolos, criando assim um simbolismo particular, com referência à sua degeneração moral.

A noção de trópico envolveu uma variedade de discussões filosóficas, estéticas, políticas, científicas e médicas, que ora debatiam o sublime e a magia da paisagem natural, ora a natureza humana e o desenvolvimento das nações, de forma a que a 
fantasia européia produzisse diferentes abordagens sobre o imperialismo político, cultural e ambiental do mundo tropical.

Assim, a história do trópico em seus primórdios envolve a produção de imagens, nos séculos XVIII e XIX com destaque para a produção de material gráfico e cartográfico, mediada por uma estética topográfica da paisagem, que foi codificada em diferentes códigos visuais, gerando com isso mapas temáticos, os primeiros sobre a natureza tropical (DRIVER \& YEOH, 2000) e posteriormente sobre a cultura humana e o seu poder de transformação dos espaços. Nesse último caso, merece destaque os trabalhos de Fernand Braudel, Claude Levi-Strauss e Pierre Monbeig que, cada qual com sua temática, produziram outras visões do trópico, considerando, então, o papel da cultura e sua relação com a natureza no processo de desenvolvimento das nações.

Assim, diferentes imagens dos trópicos foram sendo paulatinamente produzidas e cristalizadas no imaginário europeu, o que levou à produção de uma epistemologia geográfica sobre o mundo tropical, em que o amálgama foi o imperialismo.

\section{O MUNDO TROPICAL: DA ESTÉTICA DA PAISAGEM À DEGENERAÇÃO DA CIVILIZAÇÃO}

Conforme foi dito, a noção de trópico é produto de longo tempo e remonta aos séculos XVIII e XIX quando os grandes viajantes começaram a construir o conhecimento sobre o mundo tropical, particularmente com Alexander von Humboldt, influenciador de várias gerações de intelectuais franceses e ingleses por meio da noção de mundo tropical e de América. No contexto do imperialismo francês, essas imagens serviram para consolidar a Ciência Geográfica, com atenção especial ao mundo tropical, em função de seus recursos naturais, potencialidades paisagísticas e etnográficas. $\mathrm{O}$ resultado foi a criação de uma subdisciplina, a chamada "geografia tropical", importantíssima para o desenvolvimento da cartografia, das disciplinas de geografia física, geografia cultural e etnogeografia, vinculadas ao projeto imperial francês.

Neste contexto, há um paradoxo e, ao mesmo tempo, um simbolismo ambivalente, por se tratar de uma paisagem natural abundante e de grande fertilidade, mas havendo também um outro lado, marcado pela "pobreza" humana, com a subordinação do mundo tropical à órbita do hemisfério norte, particularmente a Europa (LIVINGSTONE, 1999). Essa situação material foi simbolicamente construída pelos naturalistas e viajantes, entre os quais os geógrafos desempenharam um importante papel na construção da noção de degeneração moral e física dos trópicos e pela emergência da noção de tropicalidade, intimamente associada ao processo imperial de incorporação dessa região ao modo de produção capitalista.

O mundo tropical passou a ser concebido como paradisíaco e ao mesmo tempo pestilento. A partir de meados do século XIX, o mundo tropical passou efetivamente a ser representado negativamente, como lugar de violência e destruição, onde dominavam relações sociais primitivas, com uma natureza marcada pela força da destruição, pela fatalidade climática, por feras e bestas carnívoras, além de doenças como a malária, interpretada como produto das condições de degeneração natural e moral das populações (OVIEDO, 1959, p.37).

As descrições sobre as sociedades registravam o papel negativo das condições naturais sobre o desenvolvimento tecnológico, predominando a insistência em ver a indolência da população, um modo de vida marcado pela subsistência e 
pela elevada mortalidade (KUPPERMAN, 1984). A partir de meados do século XIX passa a haver um forte discurso resultante de uma visão de mundo e de práticas estatais voltadas para a medicina tropical, tanto em função das doenças como a malária e a febre amarela, como em função do aspecto degenerativo do caráter humano resultado das condições climáticas.

Duncan (2000) descreve a situação do antigo Ceilão, atual Sri Lanka, por meio do discurso climático e higienista e marcava o cotidiano da sociedade, no qual a prática agrícola era permitida somente para os homens, pois havia o mito de que as mulheres, seres inferiores, e as condições climáticas poderiam degenerar as plantações, o que poderia comprometer a produção colonial.

Essa situação se fundamentava em um discurso machista que, associado à ideologia imperialista do determinismo da natureza sobre o caráter humano, justificava a dominação masculina e européia sobre a natureza tropical, já que também as plantas tropicais passaram a ser concebidas como inferiores às do mundo temperado. Concomitantemente, as mulheres eram segregadas, pois se pressupunha que elas possuíam baixa racionalidade e uma forte incapacidade de atuação no mundo.

Assim, haveria uma moral masculina que seria a responsável pelo desenvolvimento da civilização e pela modernização do mundo tropical, o que levou Livingstone (1991) a chamar essa prática política de "moralidade do clima e masculina", donde derivaram os conceitos de sazonalidade e aclimatação (LIVINGSTONE, 1999, p.101).

Em suma, a partir de meados do século XIX, a imagem do mundo tropical era a de um mundo antípoda ao das regiões temperadas, cristalizada pelos textos médicos que advogavam a favor da segregação e da concepção de um mundo tropical como primitivo e pobre. Emergiu, então, no contexto do imperialismo europeu, um discurso sobre o papel da raça na dominação da natureza, discurso esse que mesclava a teoria darwinista e o lamarckisns para justificar o colonialismo e a dominação européia sobre o mundo tropical. Foi quando os aborígenes passaram a ser concebidos como crianças, relíquias de uma antiga civilização, como no caso do Sri Lanka (HAECKEL, 1883, p.154).

Para Ellen Churchill Sample, os habitantes dos trópicos apresentavam baixa maturidade em relação ao mundo temperado. "Where man has remained in the tropics, with few exceptions, he has suffered arrested development. His nursery has kept him a child" (SEMPLE, 1911, p.635), justificando, assim, um discurso machista, masculino e imperial de dominação sobre as populações e a natureza do mundo tropical. A forte umidade de grande parte do mundo tropical causava a degeneração na unidade familiar e, inclusive, na virilidade masculina, visão que foi defendida por Tennent (1859, II, p.107) em seu estudo sobre a Índia, no qual as condições climáticas impunham feições delicadas e efiminadas aos homens, o que não aconteceria com as raças e os homens criados nas regiões temperadas.

No contexto cultural de início do século XX, o mundo tropical representava uma barreira ao desenvolvimento do capitalismo, de forma que seria necessária a expansão e o comando de uma raça superior como as do hemisfério norte e particularmente, àquelas ligadas aos países imperiais. Esse tema foi muito abordado pela geografia da época (SEMPLE, 1911; HUNTINGTON, 1924), que metodologicamente empregava uma mistura de determinismo ambiental e darwinismo social para demonstrar que as condições climáticas do hemisfério norte favoreciam o vigor e a inteligência, enquanto que nos trópicos, a civilização 
resultou em um fracasso racial. De acordo com Semple (1911, p.10), "The debilitating effects of heat and humidity aided by tropical diseases, soon reduce intruding peoples to the dead level of economic inefficiency characteristic of the native races". Mais à frente, continua "everywhere in the tropics the enervating effects of heat, moisture, and abundance make not only the natives averse to steady work, but start the energetic European inmigrant down the same easy descent to Avernus" (SEMPLE, 1911, p.627).

Em 1915, na primeira edição do livro Civilization and Climate, Huntington (1924), procurando dar uma contribuição "a new science of geography" (HUNTINGTON, 1924, p. 56), observou que países temperados, como os da Europa e da região nordeste dos Estados Unidos, apresentavam condições ótimas para o desenvolvimento da inteligência humana, ao contrário dos trópicos que se caracterizavam pela degeneração. Para ele, "the cause, it is generally agreed that the native races within the tropics are dull in thought and slow in action. This is true not only of the African Negroes, the South American Indians, and the people of the East Indies, but to the inhabitants of southern India and Malay peninsula" (HUNTINGTON, 1924, p.56).

Pierre Gourou (1953) registrou que o mundo tropical apresentava traços de pobreza e que era um "horror", pois o clima gerava feras terríveis (GOUROU, 1953, p.12). Sendo assim, a única alternativa era a importação de animais domesticados na Europa, pois, caso contrário, haveria deficiências na dieta alimentar. Para Gourou (1953, p.66), o mundo tropical caracterizava-se por ser uma civilização vegetal, na qual os solos são inférteis, lateríticos, representando um "pedological leprosy" (GOUROU, 1953, p.21), marcando mais uma razão para a inferioridade do mundo tropical em relação às regiões temperadas.
Para esse autor, o mundo tropical suportou um modo primitivo de civilização e de práticas agrícolas, cuja grande marca foi a civilização vegetal como na Indochina, uma civilização dependente dos ciclos naturais, de práticas primitivas de agricultura, o que explicaria a elevada densidade populacional no delta do Rio Vermelho (GOUROU, 1931, p. 82-90). Nos anos de 1930, a sociedade indochinesa era vista como uma sociedade infantil, fortemente dependente do Estado francês para a manutenção de diques, construção e manutenção das rodovias, dentre outras modernidades. Traçando uma comparação entre a China, a África, as Américas do Sul e Central, Gourou (1953, p.43-52) afirmava que as civilizações chinesa e hindu, devido à história de colonização Tamil e de invasores Arianos, apresentavam-se como as mais desenvolvidas no mundo tropical, seguidas pela civilização da América Central, onde o ambiente natural, próximo ao temperado, facilitou o desenvolvimento da civilização maia, vista como mais avançada do que outras dos trópicos.

Desenvolvia-se, assim o discurso da tropicalidade, um discurso ideológico que procurava legitimar o imperialismo francês, inglês e alemão no mundo tropical. Para o discurso científico da época, dentre eles o geográfico, a degeneração do mundo tropical, entendida como tropicalidade, era o produto histórico da relação do meio natural com a miscigenação racial. Essa construção ideológica foi muito marcante entre os anos 1880 e 1900 e se fundamentou no discurso médico, com a tese da insalubridade do mundo tropical e a aclimatação, que provocariam a degeneração física e moral nas gerações de descendentes de antigos europeus (THOMSON, 1843, p.132; BELT, 1888, p.178).

Um dos resultados desse discurso foi a criação dos Centros de Medicina Tropical (MANSON, 1898), que têm o médico Patrick Manson como o "pai" da medicina 
tropical. Esta disciplina rapidamente se disseminou nos currículos universitários na Inglaterra. Para Manson (1898, p.842), o maior problema era o elemento climático, pois o mesmo criava os "miasmas" advindos da elevada umidade e decomposição da matéria orgânica, provocando doenças específicas, que exigiam o treinamento na identificação de parasitas, vetores e "germes" que não eram conhecidos no mundo temperado.

Para o médico Ronald Ross (1910, p.7-8), a malária era o maior problema de saúde a ser resolvido no mundo tropical, sendo um verdadeiro obstáculo à civilização e ao desenvolvimento da agricultura, das cidades e do comércio das colônias.

Para Gourou (1953, p. 6), a malária explicaria o decréscimo populacional no delta do Rio Vermelho e o fracasso da França em desenvolver o sudoeste Asiático, pois causava baixa produtividade do trabalho humano. Para isso, eram necessárias práticas médicas e sanitárias modernas para a erradicação dos vetores da malária e o desenvolvimento de hábitos educacionais e higiênicos modernos na população nativa. O momento em que Gourou (1953) escrevia sobre as doenças tropicais, coincidia com o surgimento do DDT e de outras técnicas modernas para dominação da natureza tropical. Em paralelo, os países imperialistas criaram também a disciplina de agricultura e veterinária tropical, visando resolver o problema da fertilidade dos solos tropicais e da baixa produtividade.

O resultado imediato foi a criação pelo governo francês de uma agência especializada nos trópicos, encarregada de levantamentos topográficos, hidrológicos, edáficos, geológicos, além do direcionamento das universidades francesas que deveriam priorizar a realização de teses de doutorado sobre os países colonizados. Essa política estava associada a um forte esquema militar, no qual era priorizado o controle dos grandes deltas, como a do
Mekong e do Nilo. Com isso, o império francês exercia um controle eficiente sobre a circulação de pessoas, mercadorias e recursos naturais, além de formar imagens e símbolos sobre o mundo tropical e a tropicalidade, mantendo, assim, um controle político e instrumental eficiente sobre os territórios e sobre a produção das mentalidades.

O trópico, enquanto símbolo exótico no século XVIII, foi representado como ambiente de abundância, passou a ser ressignificado entre os meados dos séculos XIX e século XX, período marcado pela intensa produção de Pierre Gourou, cujo trabalho de 1953 The Tropical World, pode ser considerado como a grande síntese de uma geografia especializada e instrumentalizada no contexto do imperialismo francês.

\section{PIERRE GOUROU E A GENEALOGIA DE UMA GEOGRAFIA TROPICAL}

A geografia tropical francesa está geneticamente associada ao imperialismo francês e desenvolveu-se fortemente entre 1930 e 1970, coincidindo com a história colonial francesa. Inicialmente, a geografia tropical estava atrelada à chamada geografia colonial e somente com a dissolução das colônias francesas é que a geografia tropical adquiriu predominância nos estudos geográficos (CLAVAL, 2005).

O colonialismo francês e a necessidade de estudos geográficos sobre as colônias remontam aos séculos XVII e XVIII com a ocupação das Antilhas, das ilhas do oceano Índico e da costa africana. Com a Guerra Franco-Prussiana de 1870-71 houve uma retração nos estudos geográficos coloniais, sendo os mesmos retomados entre 1880 e 1914, com uma terceira fase entre 1930 e 1950. Ao longo dessas fases, com maior ou menor atuação, o Estado francês sempre 
se envolveu nas pesquisas geográficas, financiando expedições continentais, como a do general Bonaparte no Egito, a de Morée no Peloponeso grego, a conquista da Argélia em 1840 e no México em 1860 (GODLEWSKA, 1998). Particularmente, durante a Terceira República (1870-1914), as pesquisas geográficas e seu atrelamento às necessidades do Estado francês viabilizaram a expansão colonial.

No início do século XX, a França possuía colônias em várias partes do mundo, enfrentando sérios problemas ambientais que interferiam diretamente na produção colonial, o que exigia pesquisas científicas para resolver os problemas relacionados à baixa produtividade dos solos, assim como os relacionados às doenças tropicais, como a malária, a dengue, o cólera que ocorriam na Indochina; assim como a febre amarela na África Central e na Guiana. Os centros de medicina tropical, com médicos treinados segundo os parâmetros de Louis Pasteur, foram criados nas colônias e os profissionais da nova medicina foram deslocados para Hanoi, Dakar, Brazzaville. Juntamente com esses médicos, alguns geógrafos foram treinados para o conhecimento do ambiente tropical, fato que gerou uma ampla literatura sobre as relações entre as sociedades e o meio natural tropical, levando ao desenvolvimento da geografia médica e ao conceito de complexo patogênico de Max Sorre.

Durante os anos de 1939 a 1945 houve um significativo aumento nas pesquisas geográficas, fato que também está associado à criação, em 1939, do Centre Nacional de La Recherche Scientifique (CNRS), (CLAVAL, 2005) que passou a facilitar as pesquisas nas regiões coloniais, a tal ponto, que em 1940 o governo francês criou o Institut Français d'Afrique Noire (IFAN), cujo escritório passou a funcionar em Dakar. Depois da Primeira Guerra Mundial (1914-17), foram criadas a Office de La Recherche Scientifique pour les Territoires d Outre-Mer (ORSTOM), atualmente chamado de Institut de Recherche pour Développement (IRD). Associado aos projetos educacionais desenvolvido nos países coloniais, a exemplo do que aconteceu na própria França depois da guerra Franco-Prussiana (1870-71). Os institutos de pesquisa passaram a incentivar as pesquisas individuais, em grupo e integradas, fato que incentivou o desenvolvimento da geografia tropical francesa (CLAVAL, 2005).

Foi também nesses anos de 1930 que ocorreu a participação das missões francesas na criação de universidades e cursos de geografia nos continentes americano como no Brasil, com a USP, na África, nas Antilhas Francesas, na Guiana, Nova Caledônia e na Indochina. Foi assim que a partir de 1940 apareceram vários pioneiros na geografia tropical francesa, assim como vários outros nas ciências humanas; tais como Pierre Monbeig, Claude Levi-Strauss e Fernand Braudel que ensinaram e pesquisaram no Brasil, Jacques Richard-Molard na África de Oeste, Théodore Monod na Guiné e Pierre Gourou na Indochina, como grandes representantes da geografia tropical francesa.

Desses intelectuais, Pierre Gourou (1900-1999) pode ser considerado o grande representante da geografia tropical francesa, que com sua obra Les Paysans du delta tonkinois, de 1929, estabelece os parâmetros para os estudos das relações entre o homem e o meio na Indochina, com análise sistemática sobre a relação entre o uso das terras e as condições de vida da população. Inauguraram-se ali os estudos regionais sistemáticos, com influência marcante nos estudos de sociologia rural.

Pierre Gourou defendeu sua tese de doutoramento em dezembro de 1936, e nela procurou compreender a geografia humana no delta do Rio Vermelho, trabalho que consolidou publicações e reflexões anteriores, como a obra L'Indochine Française, de 1929, na obra Le Tonkin de 1931, 
procurou adaptar o paradigma vidaliano às condições coloniais (CLAVAL, 1998, p.98-110).

Conforme foi dito, Pierre Gourou pode ser considerado o criador da moderna noção de tropicalidade, paradigma que a exemplo da noção de orientalismo, de Said (1979) e Arnold (2000), coloca o mundo tropical em contraste com o mundo temperado, então dominante, influenciando a concepção de trópico e a postura geopolítica da França. A tropicalidade deixou de ser estética e exuberante, para tornar-se símbolo de uma imagem negativa e destrutiva. Essa imagem permitiu o atrelamento político e militar do mundo tropical aos países do mundo temperado, possibilitando a efetiva atuação do império francês na Indochina e em várias outras regiões do globo. Sob o ponto de vista metodológico, o discurso e a prática se fundamentaram nas concepções deterministas e neolamarckistas, cabendo à geografia uma posição de destaque nessa justificação de dominação imperialista e racialmente segregacionista (VITTE, 2009).

O conteúdo da tropicalidade deixou de ser o sublime e passou a ser uma imagem negativa, degradante e degenerativa, justificando o caráter "humanitário" das nações imperialistas na manutenção e controle de suas colônias tropicais. Essa imagem negativa foi fundamentada em uma postura eurocentrista e etnocentrista, com um modelo racial, de gênero masculino e feminino, visão de mundo que passou a ser aplicada aos próprios seres naturais, como a defesa da qualidade inferior da vegetação e dos animais do mundo tropical em relação aos do mundo temperado.

Essa postura marcou profundamente o desenvolvimento da geografia. Um exemplo dessa influência foi a concepção de que o relevo do mundo tropical seria um acidente climático, e enquanto que o normal seria aquele dominado pelas condições climáticas da cadeia dos Apalaches. Outro exemplo, mais recente, ocorreu na década de 1970, quando os geógrafos franceses debateram as propostas para o desenvolvimento dos países recém descolonizados na África, particularmente aqueles situados na zona do Sahel africano (LACOSTE, 1976a, 1976b, 1980).

As reflexões desenvolvidas por Pierre Gourou fundamentaram a política francesa de exploração dos recursos naturais na Indochina, particularmente a agricultura e os recursos florestais, em que o conceito de tropicalidade embasava e dava coesão às pesquisas geográficas e às políticas de exploração dos recursos naturais que controlaram a produção colonial. Esse controle político viabilizou a super-exploração dos sistemas naturais, cuja gestão estatal estava a cargo do serviço de agricultura colonial. As áreas com maior controle foram as dos deltas do Mekong e do Rio Vermelho, locais onde Pierre Gourou desenvolveu extensos e intensos trabalhos geográficos de cunho analítico, demonstrando, assim, uma estreita relação entre a pesquisa científica e o controle territorial por parte do estado francês.

O controle sobre os recursos naturais na Indochina, tanto sobre a agricultura como sobre os recursos florestais, se deu com o estado francês fundamentando-se em estudos sócio-legais e ecológicos, conduzindo a política florestal colonial, na qual definia áreas de plantação e áreas de floresta, ambas as categorias sob controle do estado (SIVARAMAKRISHNA, 1995). Em todo o território colonial e nessas áreas em particular, o estado francês exercia controle político e policial dos produtos e da classificação das terras, que deveriam ser destinadas para a agricultura, para o manejo florestal e para reservas indígenas.

A política florestal francesa na Indochina, fortemente embasada na noção de tropicalidade, tinha como matriz econômica 
a economia utilitarista e uma concepção racial que considerava que os povos indígenas eram incapazes de realizar a gestão dos recursos naturais, devendo essa ser feita pelas nações civilizadas mediante o uso de missões com técnicos e pesquisadores especializados em agricultura, pedologia e veterinária, por exemplo.

As pesquisas geográficas nas colônias francesas fundamentaram o desenvolvimento de conceitos e de legislações específicas, como foi o caso daquelas que controlavam as fazendas produtoras de grãos na Indochina. Essa legislação facilitava a alienação e o controle das terras agricultáveis no território colonial, sendo essa prática essencial para o sucesso econômico e a estabilidade política da metrópole. A legislação regulava o registro, a ocupação e o controle das propriedades, sendo um importante instrumento para a expulsão dos indígenas de suas terras, para a criação de novas propriedades. Assim, as propriedades que eram comunais passaram a ser privadas e territorialmente delimitadas por cercamentos. No caso do Vietnam, a posse da terra deixou de ser tradicional, mítica e comunal, passando a ser controlada por uma autoridade francesa, centralizadora, que fundamentava suas ações em um registro de imóveis e em cadastros utilitários (ADAMS \& HANCOCK, 1975).

Para o estado francês, esseenquadramento legal era necessário para o desenvolvimento da noção de direito privado sobre a propriedade, abrindo espaço para o investimento de bancos privados na ocupação do território vietnamita, assim como na Conchinchina, no Laos e no Cambodja. Com isso, possibilitou o investimento privado em terras coloniais, com a expansão das plantações de fumo e cana-de-açúcar, especialmente depois de 1918 (VINH LONG, 1991).
$\mathrm{Na}$ atualidade, a situação é certamente bem mais complexa que aquela da geografia tropical de meados dos séculos XIX e XX, mas apresenta algumas características que ainda marcam a concepção de trópico em termos geopolíticos e sociais, sendo a atualidade marcada por forte crise econômica, com o retorno da xenofobia e localismos com os recursos naturais, biogenéticos e energéticos emergindo novamente no topo da agenda das discussões diplomáticas e militares.

É um momento, portanto, de se rediscutir o significado da natureza agora exótica pela raridade, o papel dos recursos naturais e do patrimônio ambiental nesse mundo em mutação. Isso exige de nós uma posição teórica e epistemológica sobre o papel da política na discussão da geografia física, em particular, e seu uso no contexto social.

\section{CONSIDERAÇÕES FINAIS}

O mundo tropical é produto do Esclarecimento do século XVIII, motivado pela estética kantiana e pelo conceito de experiência estética de Schiller, sendo Alexander von Humboldt considerado o seu criador e divulgador. Nesse processo, as concepções de paisagem e de sublime, tal como desenvolvidas por Humboldt, foram fundamentais para a representação de um mundo marcado pelo exuberante. Diferentemente dos antigos, para quem o mundo tropical era produto de mitos e fantasias, a partir de Humboldt, os trópicos foram cientificamente descritos e delimitados, sendo literariamente apresentados como o paraíso e como uma possibilidade de regeneração do mundo moderno.

Com o Imperialismo e o acirramento da concorrência entre as principais nações como a Inglaterra, a França e a Alemanha, o mundo tropical passou 
a ser concebido como um espaço vital para o desenvolvimento do modo de produção capitalista das metrópoles. A partir desse momento, o exótico cede espaço a um discurso e a práticas políticas exploratórias que se embasaram na explicação ideológica da degeneração racial e natural, no determinismo ambiental e no neolamarckismo, que foram as fontes para a justificação da exploração e da dominação imperialista.

Naquele momento, tanto as plantas como os animais eram considerados degenerados e impróprios para o desenvolvimento nacional e em muitos casos cientistas, geógrafos, inclusive Pierre Gourou, chegaram a atribuir adjetivo pejorativos como o de leprosário pedológico às condições de fertilidade dos solos tropicais. Por sua vez, as populações aborígenes eram descritas como moralmente degradadas, infantis, resultado da ação do clima e da putrefação da matéria orgânica dos solos. Mesmo com a chegada de imigrantes europeus, para muitos a degeneração moral ainda predominava nos trópicos, pois ao longo dos anos essas populações foram miscigenadas com indígenas e nativos, miscigenação que associada às condições climáticas, provocava, ao longo das gerações, a degradação e a falência do modelo civilizacional hegemônico.

Nesse quadro geopolítico emergiu o conceito de tropicalidade, um conceito que denota um sentido negativo, que precisava ser sanado pelos países imperiais. $\mathrm{Na}$ construção desse conceito participaram diretamente as concepções higienistas e sanitaristas desenvolvidas por médicos e reformadores sociais, que, assombrados pela malária e por outras doenças tropicais, passaram a produzir discursos que conduziam a atuação do Estado que deveria possibilitar a resolução dos problemas médicos-sanitários por meio de ações territoriais e coloniais. Assim, foram cria- dos institutos de medicina tropical, bem como a disciplina de doenças tropicais nos cursos de medicina e cursos de agricultura tropical e geografia colonial e tropical nas universidades francesas, dentre outras.

Nesse contexto, a obra de Pierre Gourou (1900-1999) se destaca como sendo aquela que melhor explicitou os princípios de uma geografia colonial francesa e que permitiu o desenvolvimento da geografia tropical, particularmente de 1930 a 1970, coincidindo com o fim do império francês na Indochina e na África. Os trabalhos de Pierre Gourou não apenas serviram para delimitar um campo específico de trabalho, o da geografia tropical, como embasaram as ações do governo francês nas colônias, no sentido de modernizar a infra-estrutura e possibilitar a expansão da empresa capitalista. Foi uma geografia que produziu dados técnicos e que ao mesmo tempo fundamentou a expansão capitalista nas colônias a partir de uma concepção de trópico formulada por Gourou que era fortemente ligada à noção de degeneração natural e moral, que precisaria ser superada para não ocasionar sérios problemas ao projeto civilizatório francês.

\section{REFERÊNCIAS}

ADAMS, J.; HANCOCK, N. Land and economy in traditional. Vietnam. Journal of Southeast Asian History, 1(2), 1975, p. 90-98.

ARNOLD, D. The problem of nature: environment, culture and European expansion. Oxford: Blackwell, 2000.

BELT, T. The naturalist in Nicaragua. London, E. Bumpus, 1888.

CANNON, S. F. Humboldtian science. In: CANNON, S.F. (ed) Science in Culture: the early victorian period. New York: Science History Publications, 1978, p. 73-110.

CARVALHO, M. B. de. Geografia e Complexidade. Scrita Nova: Barcelona, n. 34, fev.1999. Disponível 
em: http:// www.ub.edu/geocrit/sn-34. htm. Acessado em: 02 mai. 2011.

CLAVAL, P. História da Geografia. Lisboa, Edições 70, 2003

Colonial experience and the development of tropical geography in France. Singapore Journal of Tropical Geography. 26 (3), 2005, p.289-303.

COSGROVE, D. Apollos Eye: A cartographic genealogy of the earth in the western imagination. Baltomore: Johns Hopkins University Press, 2001.

DETTELBACH, M. The face of nature: precise measurement, mapping dand sensibility in the work of Alexander von Humboldt. Studies in the History and Philosohy of the Biological dand Biomedical Sciences, 30, 1999, p. 473-504.

DRIVER, F. \& YEOH, B. (eds) Constructing the tropics: introduction. Singapore Journal of Tropical Geography. 21 (1), 2000, p. 1-5.

DUNCAN, J. S. The struggle to be temperate: climate and moral masculinity in mid-nineteenth century Ceylon. Singapore Journal of Tropical Geography, 2 (1), 2000, p. 34-47.

GODLEWSKA, A. The Napoleonic survey of Egypt. A masterpiece of cartographic compilation in early nineteenth century fieldwork. Toronto: Toronto University Press, 1988.

GOUROU, Pierre. Le Tonkian. Paris: Exposition Coloniale Internationale. 1931.

The tropical world: its social and economic conditions and its future status. London: Longmans, Green \& Co, 1953.

HAECKEL, E. A visit to Ceylon. London: Kegan Paul, Trench \& Co, 1883.

HUMBOLDT, Alexander von. Personal narrative of a journey to the Equinoctial Regions of the New Continent. London: Penguin Classics, 1995.

HUNTINGTON, E. Civilization and climate. New Haven: Yale University Press, 3 ed, 1924.

KUPPERMAN, K.O. Fear of hot climates in the anglo-american colonial experience. William and Mary Quaterly, 61, 1984, p. 213-40.

LACOSTE, Y. La géographie ça serrt d'abord à faire la guerre. Paris: Maspero, 1976a.

Enquête sur le bombardement des digues du Fleuve Rouge. Herodote. 1, 1976b, p. 86-117.
Unité et diversité du Tiers Monde, Tome II. Vallées désertes-deltas surpeuplés, Afrique et Asie Tropicales. Paris, Mapero, 1980.

LIVINGSTONE, D. The moral discourse of climate: historical considerations on race, place and virtue. Journal of Historical Geography. 17, 1991, p. 413-34.

Tropical climate and moral hygiene: the anatomy of a Victorian debate. British Journal of History of Science. 32, 1999, p. 93-110.

MARTINS, L. A naturalist's vision of the tropics: Charles Darwin and the Brazilian landscape. Singapore Journal of Tropical Geography. 21 (1), 2000, p. 19-33.

MANSON, P. Tropical diseases: a manual of the diseases of warm climates, London: Cassell, 1898.

MORAES, A. C. R. Ideologias geográficas. São Paulo: Hucitec, 1988.

NICHOLSON, M. Alexander von Humboldt and the geography of vegetation. In:

OVIEDO, G.F. Natural history of the West Indies. Chape Hill: University of Nort Carolina Press, 1959.

OVIEDO, G.F. Natural history of the West Indies. Chape Hill: University of Nort Carolina Press, 1959.

RATZEL, F. Über Naturfchilderung. Munich: Druck und Berlag, 1906. Acessado em 02 jan. 2009. Disponível em: http:/ / www.archive.org/details/ bernaturschilde01ratzel

ROSS, R. The prevention of Malaria. London: Murray, 1910.

RUSKIN, J. Of map drawing. In: COOK, E.T. \& WEDDERBURN, A. (eds) The works of John Ruskin. v. 15, London, George Allen, 1904, p. 440-62.

SANTOS, Leonel R. dos. Técnica da Natureza. Reflexões em torno de um tópico kantiano. Studia Kantiana. n. 9, dez. 2009, p. 118-161.

SAID, E. Orientalism. New York: Vintage Books, 1979.

Cultura e Imperialismo. São Paulo: Companhia das Letras, 2005.

SEMPLE, E. C. Influences of geographic environment on the basis of Ratzel's system of anthropo-geography. London: Constable, 1911.

STAFFORD, B. M. Voyage into substance. Cambridge: MIT Press, 1982. 
SIVARAMANKRISHNAN, K. Colonialism and forestry in India: imagining the past in present politics. Comparative studies in Society and History., 37, 1995, p. 3-40.

TATHAM, G. Geography in the nineteenth century. IN: TAYLOR, G. (ed.) Geography in the 20 th Century. London: Methuen, 1960, p.28-70.

TENNENT, J. E. Ceylon. London, Longman, Green, Longman \& Roberts. 3 ed, 1859.

THOMSON, A.S. Could the natives of a temperate climate colonize and increase in a tropical country and vice versa? Transactions of the Medical and Physical Society of Bombay. 6, 1843, p. 112-38.

VINH LONG, N. Before the revolution: the Vietnamese peasants under the French. New York: Columbia University Press, 1991.

VITTE, A. C. Da teleologia da natureza ao darwinismo: mutações e possibilidades interpretativas sobre a construção da geografia física moderna. Anais do XII EGAL, Montevideo, 2009.

VITTE, A. C. e SILVEIRA, R. W. D. da. Alexander von Humboldt y la genesis de la geografia física moderna. Internationale Zeitschrift für Humboldt Studien. HIN XI, 21, 2010, p. 72-84. Disponível em: http://www.uni-postsdam.de/u/romanistik/ Humboldt/hin/pdf/hin21/hin21_komplett.pdf

Recebido em: 02/05/11 Aceito em: 19/07/11 